\title{
Arms race in a cell: insights into phage-bacteria interplay in deep-sea snail holobionts
}

\section{Kun Zhou}

Ying Xu

Rui Zhang

Pei-Yuan Qian

\section{Video Byte}

Keywords: Microbiome, deep ocean, hydrothermal vents, snail holobionts, bacterial endosymbionts, phages, lysogenic infections, lytic infections, anti-viral defense, counter defense, horizontal gene transfer, multi-omics

Posted Date: October 13th, 2021

DOl: https://doi.org/10.21203/rs.3.rs-967272/v1

License: (9) This work is licensed under a Creative Commons Attribution 4.0 International License. Read Full License 


\section{Abstract}

Deep-sea hydrothermal vent ecosystems host an array of macrofauna, including many invertebrates. These animals adapt to the extreme conditions by forging endosymbiotic relationships with chemoautotrophic bacteria. Phages, viruses that infect prokaryotes, can fundamentally affect endosymbiotic bacteria, but their specific roles in deep-sea vent endosymbionts are not yet known. A recent study utilized metagenomics, transcriptomics, and proteomics to examine the endosymbiotic phages associated with the deep-sea vent snail Gigantopelta aegis. These phages infected methane- and sulfur-oxidizing bacteria, and there was evidence of both lysogenic and lytic lifecycles. The genomes also showed evidence of an arms race between bacteria and phages, with the bacteria encoding defense systems like CRISPR-Cas to break down phage DNA and the phages encoding their own anti-defense mechanisms. The phages also had horizontally acquired auxiliary metabolic genes, which could benefit replication. While laboratory experiments further examining the interplay between phages and bacteria are still needed, this study presents novel insights into phage-bacteria interactions in deep-sea vent snails. 